\title{
ISLEÑAS EN LA OBRA DE MARUJA MALLO Y JANE \\ MILLARES: PROPUESTAS DE NUEVAS IDENTIDADES Y REPRESENTACIONES FEMINISTAS DESDE LAS FRONTERAS OCCIDENTALES ${ }^{1}$
}

\author{
Yanira Hermida Martín²
}

\begin{abstract}
Isleñas en la obra de Maruja Mallo y Jane Millares: propuestas de nuevas identidades y representaciones feministas desde las fronteras occidentales

Resumen: Las artistas Maruja Mallo y Jane Millares, desde posicionamientos del indigenismo canario, miran a las isleñas construyendo una nueva manera de representar a las mujeres canarias, que permite concebirlas dentro de una nueva identidad que refleje las características de las subjetividades de las mujeres del archipiélago promoviendo la deconstrucción de los arquetipos femeninos tradicionales.

Palabras clave: indigenismo, identidad, mujeres, Islas Canarias, franquismo.

Islands in the Work of Maruja Mallo and Jane Millares: Proposals for New Identities and Feminist Representations from the Western Borders

Abstract: The artists Maruja Mallo and Jane Millares look at the islanders from positions of Canarian indigenism. They build a new way of representing Canarian women, which allows them to think about them within a new identity. At the same time, they reflect the characteristics of the subjectivities of the women of the archipelago, promoting the deconstruction of traditional feminine archetypes.

Key words: Indianism, identity, women, Canary Islands, Francoism.
\end{abstract}

\section{Introducción}

El discurso feminista occidental y hegemónico ha sido contestado y cuestionado desde los márgenes de la cultura occidental por aquellas mujeres que han percibido que un feminismo blanco, eurocéntrico y burgués permitía mantener la consolidación de un poder basado en la imposición de identidades a los colectivos subalternos y reproducir en el ámbito feminista algunos modelos de opresión propios de la herencia colonial.

\footnotetext{
${ }^{1}$ Fecha de recepción: 13/04/2018.

Fecha de aceptación: 24/05/2018.

${ }^{2}$ Doctora en Historia por la Universitat de Barcelona. Doctoranda de la Universitat de Valencia; $\square$ yahermar@alumni.uv.es.
} 
Conocer estos puntos de vista, surgidos desde los márgenes del etnocentrismo occidental, nos permite comprender la interseccionalidad de la lucha de las mujeres. Los planteamientos del feminismo que nace desde las fronteras y márgenes de la cultura occidental hegemónica nos posibilitan reflexionar sobre la compleja lucha de las mujeres en los territorios colonizados y su diálogo con las sociedades occidentales, aunando los distintos nodos de interseccionalidad (Brah 2011: 243). Esto facilita la deconstrucción de las identidades que el sistema colonial-heteropatriarcal y capitalista configura como medio de control social de las mujeres, proporcionando la diversidad y riqueza de los diferentes discursos feministas actuales en cada lugar de lucha y resistencia ante el heteropatriarcado (Segato 2003: 261).

Los movimientos feministas decoloniales han analizado como principales áreas de reflexión las poblaciones afroamericanas y latinas en EE.UU., la situación de las mujeres en Latinoamérica y el Caribe, en el continente africano y en Asia, así como las corrientes feministas en el ámbito islámico, etc. Creando un amplio abanico de enfoques, conceptos y teorías que poseen como punto de encuentro común: la configuración de discursos y estrategias propias frente al conocimiento globalizado de tintes patriarcales, capitalistas y eurocentristas evidenciando la pervivencia de mecanismos de poder insertos en la colonialidad (Martín 2018: 62-65). Desde ese lugar de crítica, pero también de encuentro interpelan a los feminismos blancos occidentales para que se revisen desde planteamientos que no alimenten la colonialidad y el sesgo eurocéntrico (Carby 2012: 209-243).

Situar nuestro enfoque dentro de las corrientes del feminismo decolonial nos facilita asimismo cuestionar el conocimiento histórico sobre las mujeres del Archipiélago Canario en el siglo XX, fomentando así una revisión crítica y actualizada de nuestras subjetividades identitarias. Una de las maneras en las que se construyen y 
tramiten las identidades es a través de la práctica artística, en el caso de Canarias, es interesante recuperar el trabajo de dos mujeres pintoras que nos permiten superar el silencio que la Historia del Arte a impuesto a las artistas (Torrent 2012: 201-203). De manera que podamos realizar una revisión de la interpretación del pasado reciente de las canarias a través de diferentes representaciones artísticas, para un primer acercamiento a esta cuestión he escogido alguna de las más relevantes: el cuadro "Mujer con cabra" creada en 1927 por Maruja Mallo durante su estancia en la isla de Tenerife y las obras "Las aguacateras" y "Viento" que pintó, durante la dictadura franquista, la artista grancanaria Jane Millares Sall.

\section{El entramado contextual: Mujeres en Canarias entre la dictadura de Primo de}

\section{Rivera y la de Franco}

Canarias es un espacio fragmentario por su condición de archipiélago, pero también es (especialmente en el periodo estudiado) un espacio de contrastes sociales, económicos y políticos tan acusados como su propia geografía de montañas y barrancos frente a planicies, de verde monte y eriales, de cumbre y mar.

Desde su conquista, la historia del archipiélago canario queda ligada a las dinámicas coloniales europeas que conectan el viejo continente con América y África. Son las islas tan preciadas por su posición geoestratégica, que las convierte en un enclave intercontinental. Desde el soporte prestado a las expediciones de Colón, hasta la configuración actual como región ultraperiférica de Europa, pasando por ser lugar de ensayo de plantaciones de cultivo como la caña azucarera, el plátano, etc. 
Es importante destacar las dinámicas migratorias de Canarias al continente americano, desde la colonización forzada de territorios hostiles en América, a través del llamado "Tributo de sangre": impuesto que gravaba el comercio canario establecido en el Reglamento Real que en 1718 instauró Felipe V para romper el monopolio comercial de la Casa de Contratación sita en Cádiz. Hasta llegar a las migraciones golondrina de los temporeros canarios en la zafra azucarera del Caribe durante el siglo XX. Estos procesos nos ayudan a destacar un aspecto fundamental que sacó a la luz la teoría decolonial: los desplazamientos de los cuerpos, como las mercancías, están regulados políticamente y esta regulación responde a los intereses del capitalismo:

Esta situación de conquista hizo que en Canarias se produjera un contacto y mezcla de gente y cultura de orígenes diferentes, que se acerca a la misma situación de "criollización", bien conocida en América, en la que intervienen tres elementos: población autóctona (tainos, arauacos en las Antillas y aborígenes canarios, postergados, esquilmados y casi extinguidos), los europeos (fundamentalmente castellanos, andaluces y portugueses en Canarias; castellanos, andaluces e "isleños" - es decir, canarios, quizá con mezcla indígena- en América) y los negros africanos (esclavos en ambos mundos). (Ortiz 2004: 201)

Cuestión fundamental para comprender el funcionamiento del triángulo de la economía colonial orquestado desde las metrópolis europeas y la vinculación de las necesidades capitalistas con la diáspora de personas desde las áreas periféricas, ya sea desde sus formas más violentas como el tráfico de personas esclavizadas hasta sus formas más diplomáticas como los acuerdos de libre circulación entre diferentes naciones.

Para comprender la relevancia de articular discursos propios desde Canarias podemos citar las palabras del historiador Domingo Garí Hayek quién destaca la de las islas como: "una sociedad que tradicionalmente se ha mantenido a medio camino a la hora de elaborar proyectos propios y de definirse a sí misma en el contexto de los 
pueblos del Estado español, y de los pueblos del mundo" (Garí 2015: 16). De ahí la necesidad de mirar al pasado de las islas desde una postura feminista y decolonial para elaborar proyectos socio-políticos propios que se ajusten a los ritmos de estos tiempos y que den respuestas a las problemáticas del archipiélago.

Para comprender el punto de inicio de este análisis, junto a la herencia de la conquista y colonización de las Islas Canarias desde el siglo XV que unió sus destino al devenir histórico del estado español, debemos destacar la relevancia de los cambios históricos más recientes desarrollados tras la II República y el levantamiento fascista que le dio fin en el archipiélago, el 18 de julio de 1936, dando paso a una larga dictadura fascista incidiendo con fuerza en la vida de las mujeres canarias.

De este momento histórico, comenzamos ahora a conocer algunas mujeres relevantes, que sobresalen por su singularidad, mujeres como la intelectual Mercedes Pinto o la primera abogada de las islas, Mercedes Machado. Isleñas que en los años 20 del siglo XX, hacían suyas las luchas feministas del ámbito estatal e internacional en el contexto de la dictadura de Primo de Rivera. Los avances de las canarias, como en el resto del estado, cristalizarían en gran parte durante la II República, instante de eclosión de la libertad femenina, y se perderían definitivamente con la dictadura de Franco. Momento en el que encontramos una ruptura profunda en la dinámica social de las islas, como el fin de la trasformación del papel socio-político de la mujer canaria y la vuelta al modelo tradicional y católico.

A rasgos generales las condiciones socio-económicas y culturales que incidían en la vida de las mujeres en el archipiélago en esta época eran: un alto índice de analfabetismo, la existencia de una rígida moral sexual que se contraponía a determinadas conductas culturalmente más laxas, que eran aceptadas en algunas 
poblaciones de las isla bajo determinadas condiciones (un ejemplo era la aceptación del concubinato) frente a la presión y el control social de los sectores más conservadores que acabarían imponiéndose bajo el ultracatolicismo de la España franquista. También, el machismo social confrontado con la emigración masiva de hombres, que propiciaba un mayor protagonismo femenino en el ámbito familiar. La valoración del trabajo de las mujeres isleñas como mano de obra barata, la invisibilización de la participación femenina en las revueltas sociales, la destrucción de los logros alcanzados por las mujeres durante la República con el establecimiento de una legislación profundamente misógina, tras el golpe de estado del 18 de julio y la represión sistemática a las mujeres que cuestionaban el orden político o social impuesto por la fuerza por el estado fascista de Franco (Hermida 2012: 24-25).

\section{Modelos alternativos para la representación de las mujeres a través del indigenismo canario}

El feminismo en su unión con el pensamiento decolonial nos permite construir un marco epistémico en el que revisemos la creación de subjetividades en torno a la población femenina de Canarias. Una de las principales aportaciones de las teorías del feminismo decolonial es su manera diversa y compleja de mostrar, denunciar y proponer alternativas frente a la interseccionalidad de las opresiones. Contribuyendo a promover nuevas construcciones identitarias creadas desde las experiencias de aquellos grupos de mujeres subalternas históricamente silenciadas: las negras, las latinas, las asiáticas, las indígenas, las bolleras, las bisexuales, las trans, las marginales, las putas, las esclavas... Quienes alzaban su voz reivindicando sus propios proyectos de 
emancipación, denunciando las opresiones que las constreñían y las violencias que poblaban su existencia. Todas ellas que, como proyecto de lucha político-social contra el patriarcado y sus aliados, elaboraron "visiones interseccionalistas de las identidades y promovieron tensiones constitutivas en la reelaboración crítica de la identidad postconvencional de las mujeres" (Guerra 2007: 61).

Por medio de estos procesos de toma de conciencia feminista y de reapropiación de un discurso político que sustente los procesos de subjetivación ${ }^{3}$ se crean nuevas identidades que nos permiten a las mujeres contar con arquetipos que nos representen en nuestra variedad y riqueza de rasgos y matices. Gracias al legado de Foucault, podemos situar desde la disciplina histórica, nuestra existencia como sujetas en el centro de nuestras investigaciones (Sánchez 2004: 44-51).

Dicho lo anterior, encontramos en las propuestas representativas en torno a las isleñas, tanto en la obra de Maruja Mallo como en la de Jane Millares, alternativas para construir subjetividades identitarias que permitan cuestionar los dictámenes tradicionales sobre las mujeres canarias. Con ese fin, podemos servirnos del feminismo decolonial como herramienta hermenéutica para analizar el contexto artístico denominado indigenismo canario, con el que las obras de estas autoras, sobre las que hablaremos, están estrechamente vinculadas.

El indigenismo en Canarias surge en torno al año 1929 en el seno de la Escuela Luján Pérez en la ciudad de Las Palmas. Este movimiento artístico se caracteriza por la búsqueda de una nueva manera de entender la canariedad:

La expresión plástica del indigenismo insular reflejaba el secular aislamiento del archipiélago respecto a la España peninsular; los artistas muestran, por primera

\footnotetext{
${ }^{3}$ Configuramos como sujetas por medio del "proceso de constitución de nuestra subjetividad" (Sánchez 2004 36).
} 
vez, la resignación- rememoración de la rendición de los canarios y su consiguiente sometimiento a los conquistadores- y la dependencia en que se hallaba sumido el isleño; y como consecuencia se da un giro en su mirada, orientándola esta vez hacia el interior y sur de la isla. (...) Lo que los pintores introducen es una visión sin paliativos del entorno, que viene a suponer, además, un severo contraste frente a la imagen turística del archipiélago que explotaba el mito de Jardín de las Hespérides... (Hernández 2001: 22)

La sociedad canaria a finales de $\operatorname{los} \operatorname{locos}$ años 20, se debatía entre diferentes arquetipos de feminidad que iban desde las "mujeres modernas" que imitaban a turistas europeas y norteamericanas con la moda a lo garçonne y de las flappers; hasta aquella idea de "mujer española" anclada a los valores conservadores y tradicionales de monárquicas y católicas (Hermida 2012: 105). Este último arquetipo femenino, el de la mujer tradicional fue, el que impuso el franquismo. Sirviéndose de la Sección Femenina cribó y censuró las manifestaciones identitarias de la población español. En Canarias se impondrán las reinterpretaciones fascistas de lo que se va a considerar como canariedad. Frente a esto, el indigenismo surge para intentar recuperar los elementos aborígenes e identitarios del mestizaje canario, que se mantuvieron tras el sincretismo franquista. Para ello, se replantean la representación de las canarias como un elemento simbólico que incorpora el esquema isla-mujer:

Los retratos y escenas de campesinas del pintor canario José Jorge Oramas, marcados étnicamente según los principios y valores temáticos de la Escuela Luján Pérez, a la que el artista perteneció, inscriben en el paisaje insular cuerpos femeninos suspendidos en un tiempo ajeno a la historia, pero poseedores de una cierta aura de cultura: la inmanencia y profundidad del cuerpo femenino surgen estrechamente conectadas con espacios rurales también sin historia, como el que había querido Hegel, y como lo quería la visión primitivista de la época. Estos cuerpos, así proyectados por la imaginación insularista, parecerían carecer de una temporalidad histórica definida y de una voz inteligible desde la visión moderna. La afirmación del arte nuevo y de su modernidad republicana hallaba en la invocación de un cierto tipo de cuerpo femenino y fecundo un índice de la concreción del espacio insular. La isla, como la mujer que la indica, se imaginaba como un lugar por excelencia vacío y latente, y esta latencia, que también reconocemos como eje importante de los discursos primitivistas desde fines del siglo XIX, es la prefiguración de un presente no solamente en sincronía con la modernidad europea, sino además utópico en el sentido más político del término. (...) Cuando el cuerpo femenino es índice de la tierra y de lo político, es decir, cuando la tierra se politiza (se territorializa) a través de una relación indicial entre 
los potenciales reproductivos del espacio y el cuerpo, ¿qué significa concretamente este cuerpo imaginado, y cómo signa, ¿cómo da cuenta de su referente terrestre? (Adrián 2007: 145)

La propuesta indigenista, aunque con la intención de crear un nuevo referente simbólico donde la mujer tenía un lugar central, no es capaz de dejar a tras muchas de las lógicas patriarcales, hasta que irrumpe la obra de una artista en concreto, Jane Millares. Desde su subjetividad como mujer, Jane Millares comienza a articular un nuevo código representativo en el que las mujeres aparecen desde una posición activa y realista. Traspasando el tradicional lugar al que son relegadas, como musas o representaciones de valores éticos y estéticos, para aparecer con piel y huesos reclamando un universo propio y rico en el que encarnan sus propias historias, superando la mirada androcéntrica de sus compañeros de profesión:

El impacto sociocultural que supone su obra es incuestionable. Su particular lenguaje será la clave de su éxito y la admiración generalizada. Este hecho es de importancia vital en la revalorización de la mujer artista y la mujer en general, que reivindica su mérito, no sólo cómo "ser capaz de crear" con igual o mayor acierto que cualquier hombre de elogio, sino cómo ser polivalente, dadora de vida y maravilla de la naturaleza en sí misma. (García 2011:3)

\section{Descubrir a la isleña en el lienzo de Maruja Mallo}

El primer ejemplo de representación de mujer canaria que he escogido es la obra "Mujer con cabra" de la artista gallega Ana María Manuela Josefa Gómez y González, conocida como Maruja Mallo (n. Lugo 1902, m. Madrid 1994) por dos razones, por un lado porque es una imagen creada por una mujer que bien demuestra los cambios en la España de la primera mitad del siglo XX, símbolo de la "mujer moderna" que abandera 
las vanguardias intelectuales en el estado español. Por otro lado, porque la autora plasma con gran sensibilidad y acierto la dicotomía social que, en torno a la construcción de la feminidad contemporánea, se gestaba en las islas.

Este cuadro es el resultado del viaje que Maruja Mallo realizó, en el año 1927, a la isla de Tenerife. La isla se encontraba en auge de creación artística en aquellos momentos, desde que a finales del XIX, una activación cultural en el archipiélago impulsara a la intelectualidad canaria a asumir los retos de la internacionalidad y la creación de redes de conocimiento y contacto con las vanguardias artísticas del momento. Iniciativa que culminaría con la celebración, en el año 1935, de la Exposición Surrealista; contando con la colaboración de André Breton, quién se apasionó por la isla a través de su amistad con Óscar Domínguez.

Maruja Mallo, con la fuerza y las inquietudes de sus 25 años, llega a la isla en un momento en el que forma parte de la llamada Primera Escuela de Vallecas. Escuela desde la que un grupo de jóvenes intentaba renovar el panorama cultural nacional desde el interior de la sociedad española. En este viaje "descubre los colores del nuevo paisaje que representa en una de sus obras más famosas: Mujer de la Cabra" (Vázquez 2012: $564)$. 


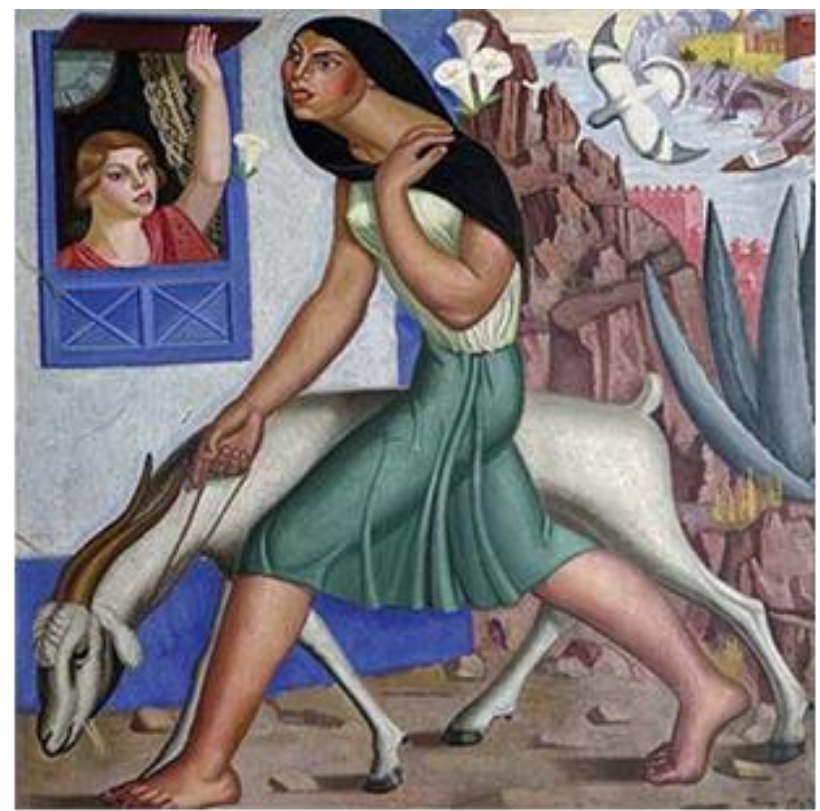

“Mujer con cabra” (1927) Óleo sobre tela. Colección Pedro Barrié de la Maza La Coruña.

Los recuerdos de las emociones y las sensaciones vividas en Canarias reaparecerán en su camino, una década después, al iniciar su exilio en Latinoamérica en 1937 ante la barbarie de la guerra civil: "Durante estos años le impactó el paisaje que encontró en América: el colorido y la exuberancia vegetal que se daban allí sólo podían tener un leve eco en la experiencia que había tenido en las Islas Canarias más de diez años antes" (Luccioni 2012: 51).

Es entre los años 1927 y 1928 cuando Maruja crea las obras que serán recogidas en su primera exposición individual en los salones de la Revista de Oriente, en esta etapa de su creación artística sin atarse a ningún -ismo, se destacan los aspectos de 
ciertas influencias del cubismo, del futurismo, del realismo mágico de Franz Roth ${ }^{4}$, de un interés por el cuerpo humano y por la representación de la realidad que la rodea:

A través de estas obras Maruja celebra el "ideal físico", no olvidemos que tanto ella, como su amiga Concha Méndez, eran grandes deportistas y además el sport es una de las señas de identidad de la nueva mujer como señalan Lily Litvak o Shirley Manzini. En 1927 pinta la Mujer de la cabra durante su estancia en Canarias. Los cuadros y estampas deportivas, afirma Rivas, están impregnadas de "un hedonismo a la vez clásico y moderno". Al ideal físico, como apuntamos, la pintora propone modelos de una humanidad "serena y triunfante en la naturaleza, en el juego y en el combate" (García 2004: 13)

En las propias palabras de Mallo, su interés pictórico, entorno al año 1928, se focalizaba en sus vivencias cotidianas y en aquella realidad que se encontraba en la calle (Kirkpatrick 2003: 249).

En "Mujer con cabra", hermosa composición pinatada en óleo sobre tela con unas dimensiones de 110 x $111 \mathrm{~cm}$, Maruja Mallo usa el paisaje canario como telón de fondo del cuadro evoca una zona del sur o una zona costera de la isla. Un paisaje dominado por la piedra abrupta que es conquistada por un cardoncillo y una pitera ${ }^{5}$ (Agave americana) sobre el que vuela una paloma común (Columba livia) puesto que las palomas endémicas de la isla (Rabiche y Turqué) se encuentran en las áreas de Laurisilva. Sobre la fachada se abren flores de campanillas blancas, que nos evocan un espacio rural en el que las enredaderas florales trepan los muros de piedra de las casas isleñas.

Es relevante resaltar como el escenario de la acción representada por Mallo conecta con elementos fundamentales del indigenismo canario, que se configuraba en

\footnotetext{
${ }^{4}$ Alejo Carpentier explica la influencia de este concepto acuñado en la obra titulada "El realismo mágico" del crítico de arte Franz Roth en la traducción al castellano realizada entre 1924 y 1925 en la Revista de Occidente. Con ese término de realismo mágico describía una nueva corriente artística caracterizada por la pintura expresionista nacida en la Alemania de entreguerras. (Carpentier 2003: 81).

${ }^{5}$ Una de las principales especies invasoras en Canarias donde era usada como valla viva para delimitar terrenos y cuya flor se aprovechaba como forraje para el ganado, principalmente vacuno. Véase: http://www.academiacanarialengua.org/diccionario/?q=pitera.
} 
las islas a finales de la década de los 20 del siglo pasado. Principalmente en el entorno grancanario de la Escuela Luján Pérez, en su búsqueda de una nueva mirada que representase la realidad interna de las islas. Estos elementos son recogidos en las palabras de Felo Monzón, una de las principales figuras de esta corriente artística, citadas por María Candelaria Hernández en uno de los principales catálogos realizados sobre dicha corriente:

\begin{abstract}
Ya habíamos renunciado a las versiones adocenadas de paisajes amables y figuras típicas al uso. Nos empeñamos, entonces, en la tarea de lograr un arte que tuviera como elementos representativos la flora canaria y los rostros vigorosos y negroides quemados por el sol. Como marco de esta síntesis colocamos una orografía agreste, pétrea, similar a la que domina en el interior de nuestras islas y cuya estructura ha sido provocada por la presión telúrica de los volcanes. Era operar lo puro, exponer con máxima precisión lo fundamental de Canarias. (Hernández 2001: 22)
\end{abstract}

Otra mención relevante de esta pintura de Mallo con el indigenismo canario, fue la reseña de la obra que el escritor tinerfeño Ernesto Pestana Nóbrega realizó en el ejemplar número 5 de la revista "La rosa de los vientos", publicado en enero de 1928 , denominando a esta obra con el nombre de Indígena canaria (Castro 2001:102).

Si continuamos observando el cuadro, podemos admirar una ventana con artesonado de madera pintada de azul añil que se abre para mostrarnos a la primera de las dos mujeres: una joven que lleva su cabello a la moda del momento. Su pelo está recogido con ondas, de un claro color castaño, esta mujer posee una blanca piel que nos informa de la ausencia de horas de trabajo bajo el implacable sol insular, y viste una camisa o vestido con un corte en sus mangas bastante moderno para la época. Del poco espacio interior de la casa, que se entrevé, predomina un reloj y una cortina con adornos calados propios de la artesanía realizada por las mujeres canarias que nos sitúa en un entorno confortable y acomodado. Frente a ella, en el primer término de la composición aparece la otra mujer, aquella que da nombre al cuadro. Una joven trabajadora que en 
sus manos lleva un pedacito de cuerda con la que sujeta una cabra. Esta mujer es claramente ejemplo de una nueva feminidad para el pueblo canario, sus pies descalzos pisan con decisión el suelo y guían el dinamismo de unas fuertes piernas, que vemos definidas a través de una falda, que desde sus rodillas se pega a la piel aportando movimiento a la acción de esta mujer. Una interpretación empoderante, revalorizando el arquetipo de $\operatorname{maga}^{6}$, que se nos presenta con piel bronceada cuya ropa sencilla, nos permite adivinar que ha dejado atrás algunas de las imposiciones tradicionales del decoro en el vestir de las isleñas: mostrando sus pantorrillas y sus brazos, aportando un aire de modernidad y jovialidad junto a su larga melena negra suelta. Una joven que con decisión camina hacia el frente, dejando atrás el espacio reservado a las mujeres en el arte tradicional, donde sólo son elementos hacia las que dirigir la mirada para contemplar su belleza o porque son depositarias/sufrientes de la acción representada.

Esta reivindicación de una nueva feminidad para las mujeres del pueblo canario, es recogida en el brillante análisis de esta obra que realiza la investigadora María Soledad Fernández Utrera, recogido en la nota 35 por Begoña Barrero en su estudio sobre la representación de la "mujer moderna" de la primera mitad del siglo XX:

Para María Soledad Fernández Utrera, la figura que aparece al fondo saludando simboliza el espacio privado asignado a la mujer, mientras que la mujer que conduce a la cabra haría lo propio con el espacio de la calle, reservado a los hombres. Y si atendemos al modo de construcción del espacio pictórico, se adivina claramente el rechazo de la artífice por el ámbito privado de la casa; Maruja lo manifiesta alejando bruscamente al espectador de este segundo plano, que queda comprimido en el fondo del cuadro: la mujer tradicional queda encajada en un espacio estrecho y opresivo. De esta manera, el espectador ha de enfrentarse directamente a la mujer que ocupa el puesto central de cuadro, una mujer que vive el espacio público y en la que se observan los rasgos representativos de sus figuras femeninas: una mujer fuerte, vigorosa, enérgica y saludable que rebosa fuerza, independencia y vida. (Barreda 2014: 237)

\footnotetext{
${ }^{6}$ Campesina, mujer del campo canario. Véase: Definición de la Academia Canaria de la Lengua en http://www.academiacanarialengua.org/palabra/mago/
} 
Otro de los análisis que se han realizado sobre esta obra destaca la relevancia de la separación de los espacios públicos y privados en el cuadro. Analizando la figura de la ventana como la mujer tradicional, sujeta a la arquitectura y al paso del tiempo que marca el gran reloj sobre su cabeza, que la somete a la pasividad y que mira a la otra mujer a la que se contrapone: la joven libre de ataduras que ocupa con paso firme el espacio público, reclamando un lugar propio en el mundo y rompiendo el rol tradicional impuesto por el patriarcado (Solar 2010: 5).

Maruja Mallo nos regala una nueva manera de representar la feminidad en el archipiélago, en la que recoge los cambios sociales que están protagonizando las tinerfeñas, en su búsqueda de nuevos arquetipos femeninos que rompan los dictados tradicionales y que culminan en el contexto de la II República, momento en el que las mujeres de la isla adquieren un protagonismo histórico relevante que las sitúa en la primera fila tanto en la vida socio-cultural como en las cuestiones políticas y en las luchas del movimiento obrero canario (Hermida 2012: 105).

\section{Jane Millares Sall: la mirada de mujer en el arte indigenista canario}

El dos de agosto de 1928, nace Jane Millares en el seno de una de las familias más relevantes de la intelectualidad grancanaria, que tras el levantamiento fascista de 1936 sería perseguida y castigada por la dictadura franquista. Fue en el contexto de la Guerra Civil, cuando la joven Jane comienza a formarse en el universo artística a través de su esfuerzo autodidacta y su gran sensibilidad creadora, camino que la llevará en el año 1955 a ser la primera artista canaria en exponer de manera individual, siendo éste el primero de los éxitos que poblaran su camino profesional. Conquistando un lugar propio 
en la Historia del Arte Canario a través de la lucha por lograr el reconocimiento en un mundo tan patriarcal mientras durante años compaginaba su labor artística con la maternidad, estableciendo una familia, siendo muy jovencita, con su compañero de vida con el que se casó cuando contaba solamente con 16 años.

La historiadora del arte Laura Teresa García Morales, quién ha estudiado su relevancia en el arte insular, nos presenta a Jane Millares destacando la relevancia de ser una isleña que construye su propia representación de feminidad canaria:

Como artista y como mujer canaria, supone uno de los mayores ejemplos de impulso y tenacidad, en el ideal humano de la libre expresión en primer lugar, que reivindica, a través de su arte; así como la dignificación de la mujer como integrante de una sociedad, en la que puede y debe manifestar su talento. (García 2011: 1)

Frente a este aspecto tan relevante del trabajo, de Jane Millares, por labrarse un papel protagonista dentro del panorama artístico en el archipiélago, debemos resaltar la dificultad de ser percibida con igualdad a los artistas varones, partiendo de su falta de formación académica en el ámbito de las artes y de tener que quebrar las cadenas impositivas del patriarcado en la sociedad de las islas durante los años de la dictadura franquista, lo que la obligará a realizar un sobre esfuerzo considerable:

Así pues, al cuidado de cuatro niños, trabajó como mujer doméstica, dedicada a su familia y las labores del hogar y como parte activa que traía dinero a su vivienda, utilizando su inteligencia e imaginación para agotar los recursos que levantaran la economía familiar.

Y es que Jane fue una adelantada de su tiempo, que supo ponerse en la piel de la sociedad a la representa(sic), como embajadora de los valores y los derechos de las mujeres canarias para salir de la marginación, reivindicando consideración y respeto, por voz de todas ellas. Se hizo defensora del patrimonio cultural, nuestra herencia primera y de las nuevas generaciones, como ninguna. Como dama luchadora, se ha manifestado frente a las injusticias de su alrededor y no ha titubeado en alzar su voz por la paz, la libertad y la rendición ante la naturaleza. (García 2011:4) 
Como ejemplo de las dificultades para que a veces se reconozca el trabajo de las mujeres artistas desde la óptica de la misoginia tradicional de nuestra cultura, es interesante destacar como el mayor de los catálogos sobre el indigenismo canario (Hernández 2001), que como hemos visto, hace una referencia directa a la obra de Maruja Mallo, no realiza mención alguna a la pintora isleña. Así el papel de Jane Millares, como única mujer integrante de la corriente indigenista canaria, queda oculto entre las referencias a sus compañeros. Mientras que otros autores reivindican su pertenencia a dicho movimiento artístico:

Y sin olvidarnos, con todo el mérito por su talento y técnicas artísticas de la hermana menor de Manolo, Jane Millares, autodidacta e íntegra artista desde su niñez, la cual ha tenido como constancia en sus razonamientos plásticos un indigenismo patente en gran parte de sus obras, desde 1950 hasta la actualidad en que no decae en sus maneras de hacer e inspirarse, tanto desde el costumbrismo pasado y atemporal hoy día, en las figuras, en las alfarerías y floras de pitas y cardones, caseríos populares, mantillas canarias — muy típicas de Gran Canariay dragos (curiosamente este ejemplar único de la flora autóctona no se usó prácticamente, solo lo dibujaron Jesús Arencibia, Felo Monzón y Oscar Domínguez, que también da nombre a una de sus obras). (Mesa 2006: 424)

Debemos destacar que, además de participar de la corriente indigenista, la pintora grancanaria experimenta también con otras corrientes como la surrealista, la realista, el arte abstracto, etc. Entre sus múltiples facetas creativas podemos destacar que, la incombustible Jane Millares, asimismo dibujaba las portadas de diferentes publicaciones, en libros de poemas de Agustín Millares Carlo (Jiménez 1994: 356), estuche discográfico de la "Antología del Timple (Vol. 3)" de Totoyo Millares (Rodríguez 2000: 3093), colaboraba con ilustraciones para la revista "Mujeres en la Isla", etc. 
La primera de las pinturas de Jane Millares, que he escogido para este pequeño acercamiento a su obra se titula "Las aguacateras" realizada en el año 1957.

Imagen 2.

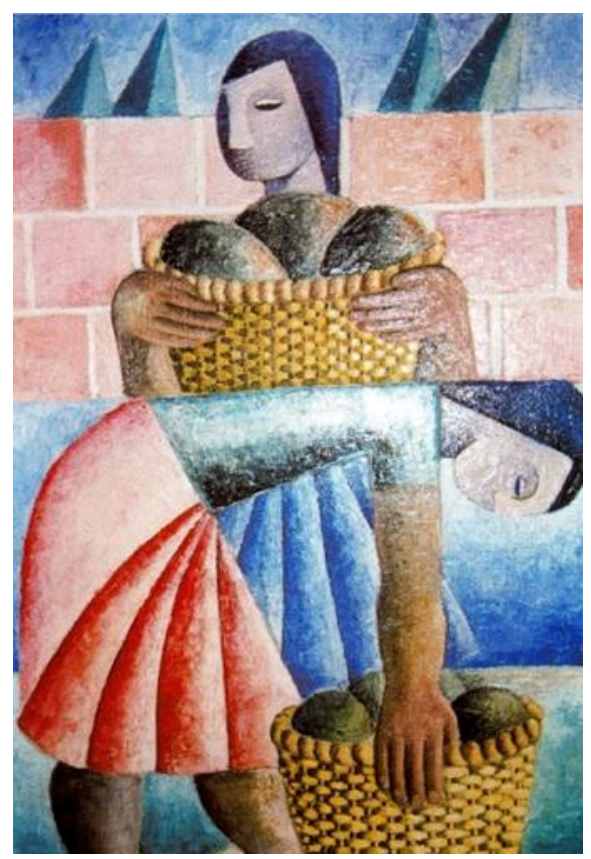

“Las aguacateras" (1957) Óleo.

La artista, representa en una composición de influencias cubistas, una escena cotidiana en la que dos mujeres recogen cestos con aguacates. Las dos figuras en trazos esquemáticos visten camisas de manga corta y faldas que cubren desde la mitad superior de sus brazos hasta su pantorrilla, manteniendo las normas de pudor impuestas en las islas por el modelo de mujer franquista que perseguirá con dureza la moda anterior del arquetipo de "mujer moderna republicana" (Hermida 2012: 216). Los brazos y las piernas musculadas de las mujeres presentan un tono oscuro, que nos habla de la piel bronceada al sol de las mujeres del campo, repitiendo el mismo tipo físico que veíamos para la isleña de Mallo. Nuevamente advirtiendo una larga melena oscura, que en esta ocasión podrían llevar recogidas en una coleta, por la falta de movimiento de sus cabellos de trazos rectos, que se contraponen a los volantes triangulares de las faldas 
que aportan movimiento a la escena. Los rostros carecen de detalles contrastando con la textura minuciosa de las cestas de mimbres y de los frutos que contienen.

Las líneas marcadas crean una composición donde protagonizan volúmenes y formas angulosas donde resaltan los colores vivos. Tras las mujeres, podemos ver la pared de un muro por la que sobresalen las hojas verdes triangulares de lo que podría ser una platanera o de una strelitzia de gran tamaño.

Las mujeres de esta pintura son protagonistas por la acción que realizan, no son un sujeto bello sobre el que depositar la mirada, son seres que trabajan, que transmiten su fuerza y su actividad, pese a eso nos transmiten la asfixiante atmósfera de la dictadura, son mujeres que trabajan duramente pero que carecen de boca, por lo que no tienen derecho a la palabra propia.

En la siguiente obra de J. Millares, un óleo titulado "El Viento" fechado en el mismo año, 1957.

Imagen 3.

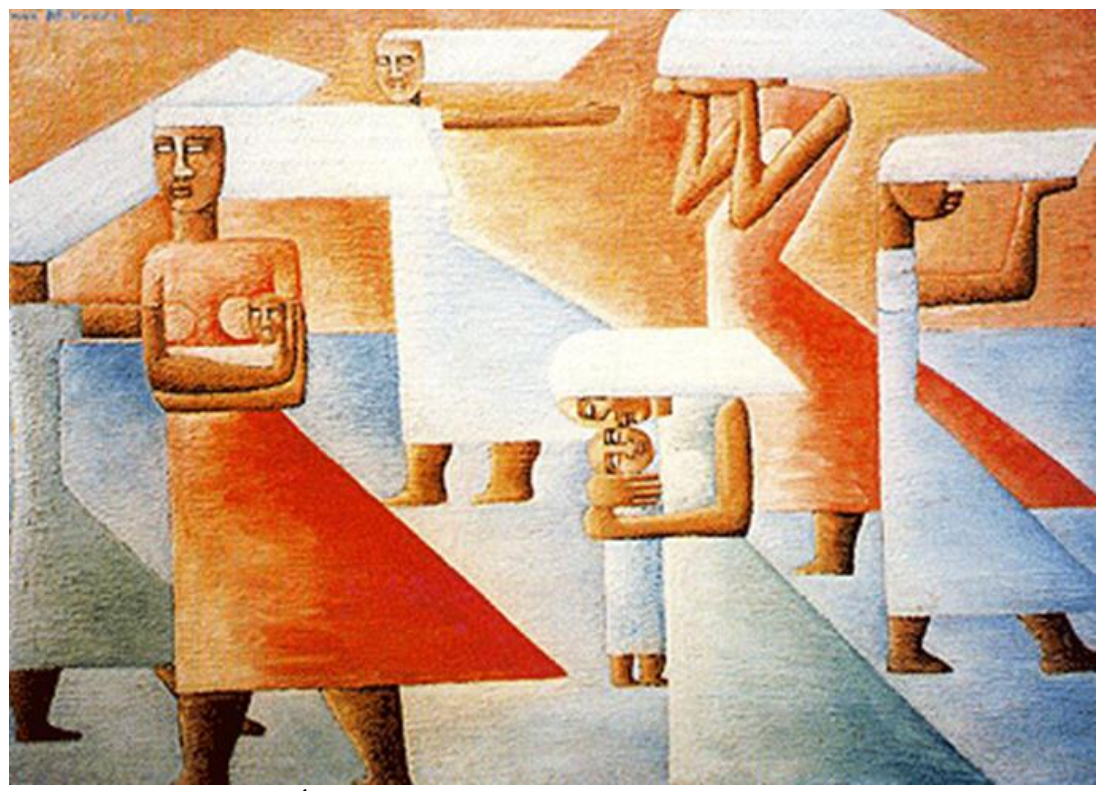

"Viento" (1957) Óleo. Colección Centro Atlántico de Arte Moderno CAAM. 
De nuevo encontramos un fondo plano, sobre él aparecen seis mujeres y dos menores en los brazos de dos de las mujeres. Jane Millares ofrece una perspectiva influenciada por el cubismo, donde las figuras nacen de trazos firmes, con colores planos y rasgos simples.

El viento, que da título al cuadro, se observa en la dirección de las telas de los vestidos y en los cabellos de las mujeres, que de manera horizontal nos marcan la fuerza del movimiento de este elemento de la naturaleza al que se enfrentan desprotegidas las seis mujeres, y del que las dos madres intentan refugiar entre sus brazos a sus criaturas. Todas las mujeres visten vestidos, dos de ellas de color ocre y el resto de un blanco azulado, ninguna lleva zapatos. Los pies descalzos sobre el suelo, este detalle junto con las piernas recias y la piel tostada nos presenta nuevamente a mujeres de clase trabajadora.

En plena dictadura franquista, Jane Millares, pinta un cuadro angustioso en el que las mujeres enfrentan la inclemencia del alisio que, enérgico, pega sobre sus rostros, su pelo y sus ropas. Solo vemos a tres de ellas intentando refugiar su cara de las embestidas del viento, una cubriendo su rostro con sus manos, otra dirigiendo su cara al lado opuesto del que sopla el aire y la última acercando su cabeza al pecho donde se encuentra con la cabeza de su bebé.

La importancia de la maternidad en la vida de Jane Millares puebla su universo particular, una maternidad que la pintora nos traslada con cariño, intimidad y a veces, con el dolor marcado del recuerdo de la pérdida de uno de sus hijos cuando aún era un bebé, unos ocho años antes de la creación de esta obra. La angustia de la pérdida y del asfixiante ambiente social franquista transita en este lienzo, en el que las mujeres se esfuerzan por mantener las envestidas con resignada entereza. 
En ambas pinturas observamos el protagonismo de las isleñas como sujetas de su propia experiencia vital, mujeres fuertes que encarnan una vida propia. En palabras de la investigadora Laura Teresa García Morales, más que mujeres son diosas de una feminidad poderosa: "Las mujeres representadas por Jane parecen más que humanas, deidades. Seres supra humanos que elevan su condición humana a la par que aman, padecen, trabajan y protegen a sus adoradas criaturas como el más valioso de los tesoros; ahí su espejo" (García 2011: 2).

Otro elemento interesante, que introduce Jane Millares, en la configuración identitaria de las isleñas, es que frente a la idea generalizada del espacio doméstico como lugar impuesto a las mujeres. El hogar que es dónde se aprenden y reproducen las estructuras del poder patriarcal, y sin perder del todo parte relevante de esta tesis, podemos detectar la ambivalencia del espacio familiar, algunas autoras feministas nos invitan a pensar también el hogar como un lugar donde generar estrategias de supervivencias propias para algunas mujeres, donde crear un espacio propio seguro frente a un papel social difuso y a menudo hostil. "Los últimos estudios feministas han recogido tanto la naturaleza contradictoria del hogar como la lucha de las mujeres para transformar el entorno de la casa” (McDowell 2000: 136). Así Jane expresa esta experiencia femenina en la que su conexión con el ámbito familiar fortalecía sus luchas profesionales, destaca el papel de su pareja al animarla a mostrar su arte y relata sus vivencias como madre y ama de casa como una faceta relevante de su existencia:

Me casé siendo una niña -dice- Con 16 años. Fui madre por primera vez con 17. Con 43 fui abuela. Lavaba, hacía la comida, limpiaba, hacía la ropa de los niños y hasta la mía. Sin saber coser, pero era muy atrevida. Pintaba en casa y ponía a mis hijos a dibujar, con música clásica de fondo. Siempre estaba llena de fuerza y energía. (Jurado 2006: 14) 


\section{Conclusiones}

El feminismo decolonial nos exhorta a traspasar por nuevos senderos para sensibilizarnos y deconstruir nuestros sesgos etnocéntricos, coloniales, sexuales, etc., aquellos que dificultan el entendimiento entre mujeres. Nos permite realizar análisis desde nuestro propio conocimiento parcial, situado en un contexto cercano en el que nuestras experiencias de vida nos permitan configurar herramientas epistemológicas desde las que pensar las existencias afines de otras mujeres y las interconexiones existentes entre las múltiples opresiones del poder que nos transitan. De forma que podamos construir un proyecto feminista en claves interactivas y dialogantes entre las mujeres de diferentes partes del planeta, entendiendo que nos encontramos inmersas en distintas imbricaciones de las opresiones del poder en los sistemas complejos de la estructura capitalista, colonial y heteropatriarcal en que vivimos. Para lo cual, posicionarnos desde las fronteras occidentales nos permiten comprender como en sociedades mestizas y criollas, como la canaria, se han ido configurando complejas subjetividades de lo que podemos entender por "ser mujer":

\footnotetext{
Hasta ahora se ha intentado mostrar la amplitud del vínculo (histórico, conceptual y político) entre las propuestas decoloniales y los nuevos feminismos. El recorrido realizado muestra, asimismo, cómo diferentes identidades subalternas llegan a hablar y a reconocerse como "diaspóricas" o fronterizas (como construidas e híbridas, pero también como propias e inexpugnables). (Pérez 2015: 111-112)
}

Desde este marco teórico es importante reelaborar un nuevo discurso representativo de nuestros elementos identitarios. Para ello, volver la mirada a las obras de aquellas autoras que se han planteado dibujar la identidad de las isleñas, como lo fueron Maruja Mallo y Jane Millares, nos posibilita encontrar nuevos elementos discursivos en los que las mujeres de las islas superen el tradicional papel de objeto de 
representación de una feminidad conservadora y reduccionista, para aparecer como sujetas de acción propia en las que encontramos un universo simbólico que nos permite acercarnos a la complejidad socio-política, cultural y económica de un conjunto de mujeres que afrontó la dureza de un contexto histórico tan dinámico como el de la primera mitad del siglo $\mathrm{XX}$, con diversas estrategias de supervivencia, con diferentes niveles de participación en el ámbito de lo público, etc. A la vez que las circunstancias históricas que las rodeaban las empujaban a replantear los roles de géneros y las ideas de feminidad, desde las rupturas favorecidas por la II República hasta la sumisa aceptación de los valores fascistas duramente impuestos por la dictadura de Franco. Dando como resultado a una nueva manera de generar resistencias y pervivencias que han formado parte del acervo femenino de las mujeres canarias en la actualidad, configurando elementos fundamentales de las identidades femeninas de las isleñas.

Recogemos la propuesta que nos lanza Avtar Brah de usar la cualidad transformadora de la cultura y sus prácticas sociales para modificar y transformar las instituciones opresivas y opresoras (Brah 2011: 42). Es innegable el papel esencial de las prácticas artísticas elaboradas desde las miradas femeninas a la hora de crear lenguajes propios y prácticas culturales alternativas. Son las artistas las que introducen un nuevo enfoque, en tanto que cuestionan los lugares comunes en los que encallan los hombres artistas a la hora de representar a las mujeres. Debemos hacer un esfuerzo por reivindicar y visibilizar la aportación artística de las mujeres se manera individual y desde una experiencia compartida (Muñoz 2009: 87). Tanto Maruja Mallo, como Jane Millares, pertenecen a un grupo de mujeres artistas que durante la segunda mitad del siglo XX lograron, no sin grandes esfuerzos, hacerse un lugar propio en los grupos del arte eminentemente masculinos. En el mismo proceso de prácticas similares y complementarias encontramos a otras figuras relevantes como Remedios Varo y 
Ángeles Santos (pintoras de la generación de Maruja Mallo) o Amalia Avia, que como Jane Millares se adentró en los caminos del arte en plena dictadura franquista (Val 2013: 692-695).

\section{Referencias bibliográficas}

Barreda López, Begoña. 2014. "Personificación e iconografía de la "mujer moderna". Sus protagonistas de principios del siglo XX en España". Trocadero, 26: 221-240. https://revistas.uca.es/index.php/trocadero/article/view/2099 [26 de febrero de 2018].

Brah, Avtar. 2011. Cartografías de la diáspora: identidades en cuestión. Madrid: Traficantes de sueños.

Carpentier, Alejo. 2003. Los pasos recobrados: ensayos de teoría y crítica literaria. Caracas: Fundacion Biblioteca Ayacuch.

Carby, Hazel V. 2012 "Mujeres blancas, ¡escuchad! El feminismo negro y los límites de la hermandad femenina". Feminismos negros. Una antología. Ed. M. Jabardo. Madrid: Traficantes de sueños. 209-243.

Castro Morales, Federico. 2001. "Enseñanzas artísticas y 'vanguardia enraizada' en el universo atlántico: 1900-1930". Catálogo de exposición El indigenismo en diálogo. Canarias-América, 1920-1950. Ed. María Candelaria Hernández Rodríguez. Las Palmas de Gran Canaria: Centro Atlántico de Arte Moderno. 85105.

Fernández Luccioni, Manuel (2012) "Maruja Mallo: artista, cronista, ¿surrealista?" Madrygal: Revista de Estudios Gallegos, 15: 45-56.

Garí, Domingo. 2015. Geopolítica, nacionalismo y tricontinentalidad. La Laguna: Ed. Latina.

García Ballesteros, Rosa Ma. 2004. "Maruja Mallo (1902-1994) De las cloacas al espacio sideral". Aposta: Revista de ciencias sociales, 13: 1-34. http://apostadigital.com/revistav3/hemeroteca/ballesteros1.pdf [23 feb. 2018].

García Morales, Laura Teresa. 2011. "Jane Millares, El reto al machismo de una pintora canaria" Revista Canarii, 20. http://www.revistacanarii.com/canarii/20/ janemillares-el-reto-al-machismo-de-una-pintora-canaria [23 de marzo de 2018].

Gómez Sánchez, Lucía. 2004. Procesos de subjetivación y movimiento feminista. Una aproximación política al análisis psicosocial de la identidad contemporánea. Doctoral dissertation. Valencia: Universitat de València. 
Guerra Palmero, María José. 2007. “¿Es inevitable el etnocentrismo? Aportaciones feministas a un debate en curso". Thémata. Revista de Filosofía, 39: 59-64. https://idus.us.es/xmlui/handle/11441/46592 [10 de enero de 2018].

Hermida Martín, Yanira. 2012. Mujeres y cambios sociales en la provincia de Santa Cruz de Tenerife. 1931-1975. Amas de casa, camaradas y marginadas. Tesis doctoral. Barcelona: Universitat de Barcelona.

Hernández Adrián, Francisco-J. 2007. "Géneros y vanguardias insulares: Canarias y Cuba en el límite de dos repúblicas”. Hispanic Research Journal, 8: 141-154.

Hernández Rodríguez, María Candelaria. 2001. El indigenismo en diálogo. CanariasAmérica, 1920-1950. Gobierno de Canarias, Las Palmas de Gran Canaria, (catálogo de exposición) Centro Atlántico de Arte Moderno.

Henríquez Jiménez, Antonio. 1994. "La poesía de Don Agustín Millares Carlo (primera parte)". Boletín Millares Carlo, 13: 355-380.

Jurado, Ángeles. 2006. “Entrevista a Jane Millares Salt”. Revista Canarias, 7: 12-16.

Kirkpatrick, Susan. 2003. Mujer, modernismo y vanguardia en España: 1898-1931. Valencia: Universitat de València.

Martín, Rocío Medina. 2018. "Feminismos periféricos, feminismos-otros: una genealogía feminista decolonial por reivindicar". Revista internacional de pensamiento político, 8: 53-79.

McDowell, Linda. 2000. Género, identidad y lugar: un estudio de las geografías feministas. Madrid: Ed. Cátedra.

Mesa, Teo. 2006. "La inexistencia de Escuelas de Arte en Canarias". Anuario de Estudios Atlánticos, 52: 407-449.

Muñoz López, Pilar. 2009. "Mujeres españolas en las artes plásticas". Arte, individuo y sociedad, 21: 73-88.

Ortiz García, Carmen. 2004. "Islas de ida y vuelta. Canarias y El Caribe en contexto colonial" LIX, 2: 195-220. http://rdtp.revistas.csic.es [5 de marzo de 2018].

Pérez Flores, Larisa. 2015. "Cuerpos y desplazamientos. Retos feministas en un marco pos/decolonial”. Cuadernos Intercambio sobre Centroamérica y el Caribe, 12: 97-115.

Sanabria Rodríguez, Inmaculada. 2000. "El documento sonoro. Nuevas perspectivas para la investigación histórica". Actas del III Coloquio de Historia CanarioAmericana. Las Palmas de Gran Canaria. 3073-3107.

Santana Domínguez, Juan Francisco. "Gritos desde el silencio" http://www.janemillaressall.com/articulos/Jane_Millares_articulo.pdf $\left[\begin{array}{ll}5 & \mathrm{de}\end{array}\right.$ marzo de 2018]. 
Segato, Rita Laura. 2003. "Identidades políticas/Alteridades históricas una crítica a las certezas del pluralismo global." RUNA: 239-275.

Torrent Esclapés, Rosalía. 2012. "El silencio como forma de violencia: Historia del Arte y mujeres". Arte y Políticas de Identidad, 6: 199-213.

Val Cubero, Alejandra. 2013. "La profesionalización de las mujeres artistas españolas. El caso de Maruja Mallo (1902-1995) y Amalia Avia (1926-2011)”. Papers: revista de sociología, 98: 0677-696.

Vázquez de Parga, Isabel Rubín. 2012. "Maruja Mallo: viajes, amistades y exilios". Más igualdad, redes para la igualdad: Congreso Internacional de la Asociación Universitaria de Estudios de las Mujeres. 559-569.

Villaverde Solar, María Dolores. 2010. "Mujer y trabajo en la pintura gallega del siglo XX". II Congreso virtual sobre historia de las mujeres. 1-16. 